\title{
Learning in project based organizations: processes, mechanisms and main challenges
}

\author{
Daniela Emiliano de Souza ${ }^{a^{*}}$ (D), Marly M. Carvalho ${ }^{\mathrm{a}}$ \\ aUniversidade de São Paulo, Escola Politécnica, São Paulo, SP, Brasil \\ *daniela.emiliano@usp.br
}

\begin{abstract}
Paper aims: Identify the mechanisms, processes, challenges and other contexts of project-based organizations that affect or are affected by knowledge management.

Originality: The literature lacks studies that assist project-based organizations in the successful use of knowledge management. We bring these analyzes to this article.

Research method: We performed a multiple case study applied to two Brazilian companies.

Main findings: The organizations face challenges due to managerial, operational, and strategic issues. The knowledge management occurs through codification and sharing of data, and both formal and informal events were identified.

Implications for theory and practice: This paper provides new guidelines for future research, also, several components that affect knowledge management were identified, so professionals will be able to design and implement models with a greater chance of success.
\end{abstract}

\section{Keywords}

Learning. Lessons Learned. Knowledge Management. Challenges. Mechanisms.

How to cite this article: Souza, D. E., \& Carvalho, M. M. (2021). Learning in project based organizations: processes, mechanisms and main challenges. Production, 31, e20200039. https://doi.org/10.1590/0103-6513.20200039

Received: Apr. 16, 2020; Accepted: June 7, 2021.

\section{1 lntroduction}

Knowledge management (KM) and organizational learning play an important role because of their impact on innovation (Alkhuraiji et al., 2016; Leseure \& Brookes, 2004), success on present (Williams, 2008) and on future projects (Yap et al., 2017), risk (McClory et al., 2017), efficiency (Grabher \& Thiel, 2015), creativity (Khedhaouria et al., 2017), clients relationship (Bernroider et al., 2014) and also assess a company to make a functional upgrading (Davies \& Brady, 2000). Studies on KM focus on the learning process (Alkhuraiji et al., 2016; Williams, 2008), however there is still a lack of studies on organizational perspective, particularly on the impact of organizational culture (Alkhuraiji et al., 2016; Duffield \& Whitty, 2016a,b), organizational structure (Daghfous, 2004; Williams, 2008), organizational climate (Alkhuraiji et al., 2016; Ghosh et al., 2012), governance (Ghosh et al., 2012; McClory et al., 2017; Reich et al., 2012) and leadership (Reich et al., 2012).

KM on project management literature is still recent (Nadae \& Monteiro de Carvalho, 2017). Obstacles to the knowledge management are commonly found on literature, and this happens due to the project temporary nature (Ghosh et al., 2012; McClory et al., 2017; Williams, 2008), because of this nature, studies point that if there's no effort to maintain the lessons after the project is finished, none will be learned (Leseure \& Brookes, 2004).

Some papers defend that for effective organizational learning to be possible the organization must have a high level of maturity (Baskerville \& Pries-Heje, 1999; von Zedtwitz, 2002), otherwise it won't translate the learning to benefits and success for the organization. When an organization is mature the knowledge management is 
part of the project management processes (Nadae \& Monteiro de Carvalho, 2017) and the implementation of a PMO helps in the learning occurrence (Bingham et al. 2015).

The organizational perspective has an important role in knowledge transfer and in learning between projects. For knowledge to be reused, knowledge transformation and absorption must be effective (Zhang \& Li, 2016). However, the concepts of learning between projects aren't well understood (Hartmann \& Dorée, 2015).

In this context, the motivations and methodologies for learning between project (Swan et al., 2010; Williams, 2008) and for stimulating the learning process (Garcias et al., 2015), demand an in-depth understanding of the organizational environment and interactions, which may allow the knowledge management (Hartmann \& Dorée, 2015), the knowledge transfer (Hartmann \& Dorée, 2015; Yan-Feng \& Xiao-Qiong, 2013), which drive this study.

Aiming at narrowing this research gap, this study explores the organizational perspective to understand the challenges faced in practicing organizational learning between projects and understand how the knowledge transfer is designed. The learning focused in this paper is the organizational learning and not individual one. This learning happens inside the project environment, by the project manager and the project participants. Also, this individual learning when correctly managed (and this is the challenge) it can be converted in organizational learning. When an organizational learning is developed it can be reused by the organization, and not only by an specific practitioner. The goals of this study were addressed through two research questions

RQ1: How do the project-based organizations acquire, manage and transfer knowledge?

RQ2: What are the main challenges the project-based organization faces while managing knowledge?

We intend to answer these questions by a multiple case study, applied to different organizations, operating in different markets, and with different cultures.

The paper is organized as follows, first we will make a brief literature review about the topic. On the third section we present the company current situation and our research methods, on the fourth section the data collection and analyses are presented, finally we discuss our results followed by the presentation of our conclusion, limitations and future implications of this paper

\section{Literature review}

The authors performed a literature review focusing on defining the concepts which underlies the knowledge management among projects, and discussion of the main topics approached which are of interest for this study. For doing so we divided this section between the knowledge management and the learning concepts.

\subsection{Learning}

Learning has a direct impact on project efficacy (Loufrani-Fedida \& Saglietto, 2016), customer responsiveness, better quality, reduction of deadlines and costs. The learning ratio is affected by the learning capacities of an organization (Ayas, 1996), also known as the absorptive capacity (Love et al., 2016).

Learning in project management does not appear to be natural due to its temporal nature (Antoni et al., 2005; Williams, 2008). Barriers to organizational learning have both an intra-organizational character, due to their temporary nature, and lack of motivation, opportunities and ability on the part of the organization (Bartsch et al., 2013). In addition, learning has a positive effect on capacity building and project performance (Chuanmin et al., 2012), project efficacy (Loufrani-Fedida \& Saglietto, 2016), customer responsiveness, better quality, reduction of deadlines and costs (Ayas, 1996), thus the learning ratio is affected by the learning capacities of an organization (Ayas, 1996), also known as the absorptive capacity (Love et al., 2016). The learning ratio, also has a relation with the behavioral changes (Chuanmin et al., 2012).

The hardship of learning between project is strengthened due to its sender/receiver perspective, and for learning to be effective the organization must address individual, social and organizational context through which projects are formed and produced. In short, the hardship is enhanced by the separation among learning and projects, the learning process must be part of the project (Hartmann \& Dorée, 2015).

The effect of effective communication and project learning on the reuse of project knowledge will directly affect the project performance. It is possible to perceive the project meetings, physical mock-up units, informal gathering, information and communication tools, and brainstorming sessions as communicators enablers, and the factors that stimulate project learning are project mistakes, obstacles, self-improvement, willingness to share experiences with others, and working as a team (Yap et al., 2017). 
There is also the impact of time pressure on creativity, which is rather important on the R\&D results, learning and knowledge moderate this effect. Thus, the learning orientation and knowledge sourcing behaviors pose a direct impact in reducing team members' experience of time pressure and in stimulating their creativity (Khedhaouria et al., 2017).

Through the learning process an organization is capable of fitting in any changing environment, and having a broad view of the system looking upon the Triple bottom line concepts, when social environmental and economic aspects are considered together (Sastre-Merino et al., 2013).

There is also a urgency of the following processes for the learning: reflection, integration, systems thinking, participation and negotiation (Mahanty et al., 2007). Furthermore, the social learning and its results depend directly on the participation and management of the most important stakeholders, besides that, the leader is fundamental for the learning process being capable of inhibiting or facilitating the process (Sastre-Merino et al., 2013).

\subsection{Knowledge management}

The essence of project management lies in the ability to continually enhance the underlying knowledge base, known as learning ability. Which means that the individuals transmit their learning to others and the accumulated knowledge acquired is incorporated into the organization (Ayas, 1996).

Knowledge management has been defined as the process of converting personal information and experiences into collective knowledge through the systematic management of information and learning, allowing the sharing of this knowledge throughout the organization (Association for Project Management, 2012)

The literature also addresses knowledge transfer (Bell et al., 2016) and knowledge creation (Grigoriou \& Rothaermel, 2017) concepts, however the concepts about knowledge creation applied to learning between projects isn't well understood (Hartmann \& Dorée, 2015).

Knowledge management and knowledge transfer aim to create knowledge assets out of information and expertise, and turn this knowledge into a competitive advantage (Aerts et al., 2017). For knowledge to be reused, knowledge transformation and absorption must be effective (Zhang \& Li, 2016).

The literature defines three knowledge owners: the individual, group and organization (McClory et al., 2017; Nonaka \& Takeuchi, 1997). The knowledge, in individual level can be tacit when it is personal, or explicit when it can be described through words, numbers or codes (Nonaka \& Takeuchi, 1997). The tacit knowledge needs to be managed to became an explicit knowledge, so it can be shared with the group and organization afterwards (McClory et al., 2017; Nonaka \& Takeuchi, 1997).

Knowledge management appears to be important for the competitive environment, and it is necessary to develop and maintain organizational skills (Baskerville \& Pries-Heje, 1999; Ravichandran \& Rai, 2003).

\subsection{Organization Knowledge}

Knowledge management must be directly connected to the organization's strategies and goals and be clearly expressed for its correct implementation. Analogous to this, the degree of innovation of the organization will affect the way it performs knowledge management, and the type of knowledge the organization seeks to maintain (Leseure \& Brookes, 2004).

In situations where the degree of heterogeneity of knowledge is very high, communication difficulties and team collaboration increase, impacting on the enthusiasm of team members, leading to negative team performance (Zhang \& Li, 2016).

Changes in organization, end of relationship with a long-term supplier, end of project, turnover and organizational growth appear to have a direct impact on knowledge management (Leseure \& Brookes, 2004). Knowledge practices are affected by both social and technical issues (Andersen \& Vidar Hanstad, 2013; Dubinskas, 1993; Reich et al., 2012).

The biggest barrier to knowledge transfer lies in the lack of motivation of the project team to pass it on (Bell et al., 2016). This motivation is affected by organizational synergy (Stephens \& Carmeli, 2016; Zhang \& Li, 2016), organizational skills (Baskerville \& Pries-Heje, 1999) for the clarity and transparency of knowledge ownership, and organizational structure (Andersen \& Vidar Hanstad, 2013; Medina \& Medina, 2017).

The literature approaches several tools and processes which are valuable for the knowledge management (Baskerville \& Pries-Heje, 1999; Duffield \& Whitty, 2016a,b; Mahanty et al., 2007; von Zedtwitz, 2002). 


\subsection{Tools and processes}

The literature studies several tools for knowledge management and organizational learning, through postproject reviews which conclude that the most efficient way of transferring knowledge is through the project practitioner rotation among projects (von Zedtwitz, 2002).

Despite information and communication technologies (ICT) appear as important when disseminating knowledge and building capacities (Loufrani-Fedida \& Saglietto, 2016), the ICTs are not enough by themselves for learning occurrence (Bingham et al., 2015).

Studying knowledge management through storytelling, it is possible to see that the results obtained from this tool are directly linked to the capabilities of the account and the facilitating technology used to propagate the story (Duffiels \& Whitty, 2016b).

There are three micro practices of codification, support and knowledge sharing: formalization of project management; post-project analysis; project documentation and its storage. Hence, ICTs are powerful tools, the right usage of them allows the individual to recognize the learning generated through the project and these tools also have the capacity of making the tacit and individual knowledge become the organizational knowledge (Loufrani-Fedida \& Saglietto, 2016).

\section{Reaserch methods}

This study aims at exploring the organizational perspective to understand the challenges faced in the practice of learning between project and understand how the knowledge transfer is designed. For this purpose, we selected for our study a qualitative approach and an exploratory research strategy (Nadae \& Monteiro de Carvalho, 2017), based on multiple-case study methods, because of its ability to address the connections between knowledge management (Ghosh et al., 2012).Besides, the case study is useful for building theory, as this methodology assesses the understanding of the main concepts of the subject studied (Eisenhardt, 1989; Eisenhardt \& Graebner, 2007).

\subsection{Cases selection}

\subsubsection{Sampling}

According to Eisenhardt (1989) the population selection is crucial, because this selection controls the variation and assesses while defining the generalization of the results. The selection of cases followed Eisenhardt \& Graebner (2007), thus, the theoretical sampling process was carried out. In this process, the cases are selected because they are appropriate to the universe of analysis and will assist in understanding and clarifying the research constructs.

The key criteria for the selection of companies were the routine of projects, the existence of practice in knowledge management. In addition to these criteria, the company's availability in collaboration with the research was also analyzed. This collaboration included making the desired profiles available at each stage, information, and company documents.

For a better exploration of the research universe, two cases were selected intentionally in companies of different segments and sizes. To achieve greater generalization of the data and understand better the universe of analyses different profiles were interviewed among the respondents. In this way it was possible to capture the change in perception by levels of the structure, and the differences of knowledge management practice among the two fields of application.

The study is applied into two Brazilian organizations, which have different culture aspects and are present in different business markets, a descriptive of the organizations and the projects studied are described on Table 1. Both brazilian organizations operate in project management and execution. But their profiles contrast, thus bringing greater wealth to the data collected, and generating a greater variety of the data collected.

For each project we analyzed the project data, as the initial and final project scope, learning report, and other documentations, and carried semi-structured interviews with employees in several hierarchical positions (the board, engineers, and analysts) between December/2017 and January/2018, all of them were recorded. The questionnaire that helped the individual interviews is available in the Appendix A.

The companies will remain confidential, and they will be named as company $A$ and $B$.

Company A - ls a big public Brazilian organization, present in the transportation sector, which also employs construction projects, for the multiple case study we selected projects for three subway stations implementation. 
Table 1. Sample characteristics.

\begin{tabular}{cccc}
\hline Organization & Sector & Projects aim & Interviewees \\
\hline A & Transportation & lmplementations of subway station & 4 \\
B & Systems & $\begin{array}{c}\text { Automation Technology } \\
\text { actualization }\end{array}$ & 5 \\
\hline
\end{tabular}

We interviewed a coordinator, and three engineers. We also had access to technical visit report of both projects, which included costs, delays and evolution of each project.

Company B is a national engineering company with 25 years of market. It has a multidisciplinary team of approximately 180 professionals. Its focus is to help its customers through technology to exceed their limits. And this purpose is achieved through the viability of innovative production processes, built on the combination of technology. It was selected 3 projects with the same objective, actualizing the automation technology of different organizations. We interviewed 5 employees in different kinds of levels among the organization. We had access to the biggest challenges among the projects, the scope, performance report, and the delivery report of the projects, part of the data is due to observations performed by the researchers.

\subsubsection{Data collection and data analysis}

After setting the parameters to choose the organization and cases to be studied, the researcher must design the instrument for data collection (Eisenhardt, 1989). Following Morioka et al. (2018) we collected the data through a multiple data collection strategy, so it assisted us to ensure the validity of the research (Yin, 2010). Main data sources are semi-structured interviews, these were conducted supported by a questionnaire (script available in the Appendix A), and the interviews were conducted in person, or by call conference. The semi structured interviews were combined with analysis of documents shared by the organization which were built during the development of these projects.

The semi structured interviews were developed based on research instrument composed by open and close questions grounded in the literature summarized in Section 2. In the interview we focused on understanding how the organization threats and transfers knowledge (Choi \& Lee, 2003), why the organization is transferring knowledge, the methods to do it, and the value the employee gives to the knowledge management (FerrerasMéndez et al., 2016). We also wanted to understand the level of importance the organization gives to the knowledge transfer after the ending of a project, and its frequency (von Zedtwitz, 2002), finally we adapted the research questions to include the storytelling tool concepts (Duffield \& Whitty, 2016b). For the purposes of this article, the knowledge studied is the knowledge acquired by a project member in a project. This knowledge has the potential to be reused and reapplied in other projects and processes. All the respondents had access to a questionnaire before the interviews, the questionnaire was elaborated with multiple choice questions, to facilitate the codification of the same, besides that they had the opportunity to give a broad opinion and they were asked to tell the story of the project. With this, our research design allows us to gather the information needed for our research scope with the advantage of enabling an open answer due to the storytelling tool.

In multiple case studies, one of the most challenging tasks is to mitigate the bias through the triangulation of multiples data sources (Yin, 2010) and assuring that the data analysis is driven to a distinct problem. The content analysis was performed on the transcribed interviews, which were codified and had it content analyzed, after this process was finished all the results were interpreted (Morioka et al., 2018).

The coding of data followed the stages of the interviews and included four blocks of parameters, following Table 2 derived from the literature review. It initiated with the methodology used to transfer knowledge, passing through the importance for the organization and for the individual, and finally the motivation captured to manage the knowledge.

\section{Results}

\subsection{Company A}

Before the interviews, we had access to several documentations. All the projects started in 2010 and finished with delays and increased costs in 2017. The company had lost the first reports, so we just had access to the reports after 2014. Both projects had a 25\% increase in their cost and were first planned to be finished in 2015 . 


\begin{tabular}{|c|c|c|}
\hline Construct & Parameters & References \\
\hline \multirow{3}{*}{ Mechanisms for Knowledge Management } & Codification; & \multirow{3}{*}{ (Loufrani-Fedida \& Saglietto, 2016) } \\
\hline & Socialization; & \\
\hline & Exploration & \\
\hline \multirow{7}{*}{ Motivation for Knowledge Management } & Project Management; & \multirow{7}{*}{ (Carvalho \& Rabechini Junior, 2015) } \\
\hline & Products and Services; & \\
\hline & Team's impact; & \\
\hline & Current Business Impact; & \\
\hline & Future Business 1mpact; & \\
\hline & Client Impact; & \\
\hline & Sustainability & \\
\hline \multirow{6}{*}{ Challenges for Knowledge Management } & Learning; & \multirow{6}{*}{ (Duffield \& Whitty, 2016a,b) } \\
\hline & Culture; & \\
\hline & Social; & \\
\hline & Systems; & \\
\hline & Processes; & \\
\hline & Infrastructure & \\
\hline
\end{tabular}

We conducted four interviews, three of them with engineers, split in different occupations, the interviewee 1 is a civil engineer, the second is a planning engineer, and the third is a field engineer, we also interviewed the project's coordinator. All of them were involved in the project since its beginning.

All the interviewees were informed about the project they were being interviewed, and all of them had access to the questionnaire before the interviews.

\subsubsection{Mechanisms for knowledge management}

In respect to the questionnaire all the interviews informed that the knowledge gathered among projects were well codified and shared, but not all of them believed that there was an easy access to it. The collaborators also informed a missed focus on PPR (post project reviews) informing that the organization didn't perform them, and they believed it should have been done, they also added that the information sharing happened through informal meetings.

The coordinator pointed out that the company A was implementing the lesson learning tools, but knowledge management was not achieved, he also perceived that the acquisition and reapplication of tacit knowledge was achieved and reapplied to other projects.

The engineer \# 3 asserted that all the learning acquired during the project was obtained through researches/ studies carried out by her, since there are no training courses directed to the project activities focused on her position. Also, the engineer \#3 believed that the role of the board in the application of knowledge management came from three phases: leadership awareness; training and quality qualification; demand the application of what was trained. It is verified that the interviewee placed great emphasis on the application of learning concepts.

\subsubsection{Motivation for knowledge management}

All the respondents had different opinions about the benefits of the projects, the same happened when discussing the source of their learning among projects, if it were the mistakes during projects or the hits that resulted in knowledge that may impact more on the result of the projects.

The engineer \#2, who works with planning, asserted that the learning within these projects were concentrated on planning and risk management. The engineer \#2 pointed out that the time pressure caused a negative impact on the planning, which became inefficient and several unexpected modifications needed to be performed. She also asserted that the benefits of learning were perceived in administrative and strategic issues, since the operational was well established and the activities did not have many possibilities of changes. The most impacting learning for her was the risk management which is now being applied in other projects. The engineer \#3 didn't share this vision, she asserted that the challenges faced in the field during the projects were all very similar and happened in all projects. 


\subsubsection{Challenges for knowledge management}

The coordinator indicated that the perceived challenges were strategic, administrative and operational, and he also addressed the impossibility of separating these challenges, because one leads to another, they operated as a chain.

The interviewee stated that knowledge management was effective within his area but when migrating to other departments, knowledge management was hampered. The interviewee did not know what could be done to improve knowledge management, since it was a strategic decision.

The engineer \# 1 pointed out a gap on their communication, that despite all the regulations and directives implemented by this organization, the lack of precise communication and use of the right communication channel resulted on an inefficient knowledge management. He also pointed out that the lesson learning tool was still on its embryonic phase and its use was not disseminated among the whole organization, the second engineer complemented asserting that the knowledge management was not effective because of the lack of capability and immaturity of the involved ones to manage the acquired knowledge.

The engineer \# 1 asserted that the political crises through which Brazil passed during the project implementation affected their performance because several hired organizations bankrupted during the project and other audits were necessary, impacting on cost and length of the projects. Because of this turning over, the knowledge acquired was lost along the project development. He also believed that among all the difficulties, the most challenging activity for knowledge transfer happened due to people management, given the vision of each actor in the process itself. People with ages, indoctrinations, intellectual abilities and especially understanding were completely different from one another, working in the same project.

Sharing the same vision, the engineer \#2 asserted that knowledge was kept on the tacit level and was not transferred to others. She also added that sometimes another employee had to rediscover the solution, to address the challenge already faced before.

The engineer \#3 claimed that the leadership of the organization was focused on implementing the lesson learning tool and achieved knowledge management, but the level below didn't seem to share this vision once they did not facilitate her participation in their training, they actually kept her from performing the training at the requested moment. They asserted that she couldn't perform the training that time because she had more critical activities to do. This showed a gap between the vision imposed by the company's board and management. The interviewee also stated that her management did not understand either the real need for project learning, or its benefits.

Regarding the barriers, the engineer claimed to find great challenges at the beginning of every project, according to her: "every project seems to be the first one carried out by the company..." This was due to the incidence of the same operational problems that caused rework and increased cost and scope.

\subsection{Company B}

The company had a well-established process for documenting the stages of the project to be carried out, based on 1S09000, and we had access to the files from each project.

We conducted five interviews, three of them with engineers, split in different occupations, the interviewee 1 was one of the directors of the organization, who participated in projects B2 and B3, the second interviewee was the senior technical engineer who was responsible for all the technical features from the projects.

All the interviewees were informed about the project they were being interviewed, and all of them had access to the questionnaire before the interviews.

The process for the company documentation was well known by the employees, but the way they were kept didn't facilitate the dissemination of the knowledge, many documents were in press, and even the digitalized ones did not have either an easy access for all sectors within the organization, or an integration of documents into the organization's system.

\subsubsection{Mechanism for Knowledge Management}

The organization B had a methodology implanted based on ISO 9000, this documentation is composed of several criteria and features, one of them is the Critical analysis, on this stage the project's participants should fulfill with the project group learning. But, this stage has a challenge, it can only be fulfilled after the other stages are fulfilled. With the questionnaire respondents we verified that there was an agreement that there was a well-established documentation process, and the knowledge was shared through them. 
The interviewee \# 1 asserted that the organization, which worked with systems and emergent technologies, kept trying to learn through special meetings with external suppliers, and benchmarking. Besides the documentation fulfilling, the organization attempted to share the knowledge through informal meeting.

The Interviewee \#2 was the technical leader of the project B3, he stated that despite not having post-project review formally established, informal conversations with strategic focus were held.

The Interviewee \#4 believed that in order to improve the knowledge management, there were possible actions for best practices in knowledge management, besides the use of tools which may help the effective management of knowledge.

\subsubsection{Motivation for Knowledge Management}

All the interviewees asserted that there was no established procedure for the post project reviews, but they believed that they should perform it. There was no agreement among the interviewees about what should be the focus with the post project reviews.

The interviewees \#2, and \#3 which were responsible for the operational issues were convicted that post project reviews should focus on strategic features. While the interviewee \#4, who had managerial and strategic obligations, believed that the post project reviews would add value when focused on managerial and operational issues. The interviewee \#1 who was responsible for the strategic decisions asserted that the value creation through the knowledge management also asserted that the learning should have focus neither on operational and managerial issues nor on strategic ones, because the learning happened in each of these features, but the learning which would most impact the following projects were the ones focusing on mistakes. The other interviewees believed that either mistakes or hits were sources of knowledge.

\subsubsection{Challenges for knowledge management}

As mentioned before the organization had a methodology of documenting the knowledge obtained in the project, but the documentation was held in press, this learning was not coded, and not accessible to all the organization. Because of this, among the organization's culture the employees didn't look for the knowledge gained from similar past projects.

The interviewee \# 1 believed that the lesson learning process was well established, the employees knew the existence of the process and how to fulfill it, but it was not cultural for the organization to address the activities needed during the project's daily routine.

The interviewee also added that there were 2 scenarios that interfered in knowledge management, when the organization didn't have many projects, because then the organization focused on the commercial activities, and the other was when the organization's portfolio was full, because there was no time to focus on learning among projects. Besides these challenges, the interviewee \# 1 also addressed that he didn't know how to measure the knowledge management impact, and its value was uncertain.

It was perceived during the second interview that mind-set was also a challenge, the technical leader addressed that he didn't learn with the projects because he performed activities he was already used to, so he didn't have technical challenges.

The interviewee \#3 also stated that knowledge transfer usually occurred among project members. The transfer of knowledge to the rest of the company was hampered by the availability of allocation.

The interviewee \#4 saw the documentation fulfilling as challenging in the daily routine, he also added that the knowledge obtained remained at the tacit level, and in situations that for similar projects the organization employed different employees the subsequent project would go through difficulties, sometimes the same ones.

He also pointed that for the knowledge management to be effective, the organization must employ someone to lead and audit the knowledge management and transfer. This employee must be empowered to require certain actions, otherwise the knowledge management would always be on low priority.

\subsection{Cross Cases Comparison}

All the organizations were analyzed in relation to the mechanisms to manage and transfer knowledge, and the motivations and challenges to do so. We coded the results among the parameters selected considering the existing literature (Carvalho \& Rabechini Junior, 2015; Duffield \& Whitty, 2016a,b; Loufrani-Fedida \& Saglietto, 2016). Table 3 presents the potential of each parameter studied in the perception of the analyzed organizations. 
Table 3. Coding Results.

\begin{tabular}{|c|c|c|c|}
\hline \multirow{2}{*}{ Construct } & \multirow{2}{*}{ Parameters } & \multirow{2}{*}{$\begin{array}{c}\text { Perception of Interviewees } \\
\text { Org. A }\end{array}$} & \multirow{2}{*}{$\begin{array}{c}\text { Perception of Interviewees } \\
\text { Org. B }\end{array}$} \\
\hline & & & \\
\hline \multirow{3}{*}{ Mechanisms for knowledge management } & Codification; & Highly & Highly \\
\hline & Socialization; & Highly & Highly \\
\hline & Exploration & Little & Little \\
\hline \multirow{7}{*}{ Motivation for Knowledge Management } & Project Management; & Generally & Highly \\
\hline & Products and Services; & Little & Little \\
\hline & Team’s impact; & Little & Little \\
\hline & Current Business 1mpact; & Little & Generally \\
\hline & Future Business Impact; & Generally & Generally \\
\hline & Client Impact; & Little & Generally \\
\hline & Sustainability & Little & Little \\
\hline \multirow{6}{*}{ Challenges for knowledge Management } & Learning; & Little & Little \\
\hline & Culture; & Generally & Little \\
\hline & Social; & Generally & Little \\
\hline & Systems; & Generally & Little \\
\hline & Processes; & Highly & Generally \\
\hline & Infrastructure & Little & Little \\
\hline
\end{tabular}

The parameters that were perceived by four or five project members are mentioned as being highly perceived. The parameters that were perceived by two or three members of the project are mentioned as generally perceived. The parameters that were perceived by a member of the project or less are mentioned as little perceived.

It is visible that the codification and socialization are the mechanisms disseminated in both organizations, exploration is immature, and unknown for most part of the interviewers.

Besides that, both companies remarked that there are improvements to be made in order to better manage their knowledge.

Company B seemed more proficient and accurate in knowledge management mechanisms, since there is a well-known process for documentation and they hold constant meetings with external suppliers and benchmarking, whereas Company A showed a little more confusion towards knowledge management and pointed out a lack of trainings for specific positions in the company, thus making them dependent on self-study for improvement. Both said there is no easy access to the information gathered, nor post-project review, though.

As well as the other, Company B stated that a PPR procedures were important, even though they couldn't reach an agreement either on how the Post-Project Review should be performed or on what focus it should have. The employees tended to bring the focus closer to their area of interest, which showed little or narrow view towards the entire perspective on the problem.

Since Company B follows the Quality and Warranty Management based on ISO 9000, the employees seem satisfied with how the documentation and process work and how the information is shared, yet Company $\mathrm{A}$ employees see that learning lessons tools are applied but the knowledge management isn't achieved while tacit knowledge was achieved and reapplied, there was an emphasis on improving the application and applicability of what is learned.

Regarding the motivation for knowledge management, our codification had a focus on success dimensions, and it's clear that there is no consensus among the organizations, and neither among the members within the organization. But, in both cases we didn't identified a motivation regarding the sustainability aspects, nor the team impact. For organization A there's also no impact perceived on the clients, that probably happens due the fact that is a public organization. Project management and future business impact seems to be the most perceived benefits for manage the knowledge.

Focusing on the divergence of opinions regarding the motivation for knowledge management while one engineer in organization A stated that the pressure of time was a problem that made the process less efficient and reflected on several unexpected modifications to the original idea, another engineer stated that the foregone challenges were all too similar and happened in all the projects.

Referring to the challenges each company faced, we could see that Company A had a bigger problem with communication and transferring knowledge, each sector had a different point of view regarding knowledge management and the implementation of lessons learning tools, as well as the lack of maturity and capability to manage knowledge of some employees. 
The coding pointed that in both organization the most visible challenges happened due the cultural aspects, followed by processes and systems issues. Learning and infrastructure doesn't seem so important to the interviewers as impacting the knowledge management.

The interviewers from organization A also pointed challenges that they didn't know how to deal with them because they seemed cyclic, they also reckon the economical and political crisis of the country as a major fact for the development and success of the projects, it affected their deadline and their acquired knowledge, because many investors and companies that were part of the initial project bankrupted. The biggest problem reported was that each project was treated as if it were the first, because there was a high incidence of the same operational problems.

Company B seemed a little more confused in defining their own challenges, they understood the process of documentation and knew how to proceed, but they didn't go after the information that was stored, probably because they couldn't see the importance in it. They also mentioned that knowledge was kept within each sector or project members instead of being transferred to all areas and employees. Another problem was due to the company's demands and priorities, because there was no organization towards the learning process, if the demand was too high, there was no time to transfer knowledge, if the demand was too low, they focused on commercial purposes rather than on learning.

Finally, some employees couldn't see their learning through the projects, because they had been doing the same task for too long or too many times, so they didn't fully appreciate what could be learned during the projects, thus not transferring what could be relevant information.

\section{Discussion}

The both organizations have mechanisms to learn and manage the knowledge among projects, in agreement with Loufrani-Fedida \& Saglieto (2016). There are existing both structured and non-structured mechanisms. Table 4 summarizes the processes and mechanisms adopted by the organizations.

Table 4. Existent mechanisms in the organizations $\mathrm{A}$ and $\mathrm{B}$.

\begin{tabular}{|c|c|c|}
\hline & Organization A & Organization B \\
\hline \multirow{4}{*}{ Process of acquiring and managing knowledge } & Codification and sharing of knowledge; & Codification of knowledge based on 1S0 9000; \\
\hline & Informal meeting for knowledge transfer; & $\begin{array}{l}\text { Formal meeting with suppliers and partners is } \\
\text { used to acquire knowledge; }\end{array}$ \\
\hline & Lessons learned tool; & $\begin{array}{l}\text { Internal informal meetings are used to transfer } \\
\text { knowledge among the project members; }\end{array}$ \\
\hline & $\begin{array}{l}\text { Researches, studies, and direct experience } \\
\text { generate individual knowledge. }\end{array}$ & $\begin{array}{l}\text { Both mistakes and hits generate individual } \\
\text { knowledge, but knowledge generated by } \\
\text { mistakes has a high impact on next projects } \\
\text { execution. }\end{array}$ \\
\hline
\end{tabular}

In both companies we perceived a hardship to effective learning and knowledge management, we found evidences supporting that the knowledge management is difficult when the organization has many projects, or other emergent activities to be performed (Duffield \& Whitty, 2016a,b), and because of this the knowledge management being so prioritized, is consequently not done. But, interviewing the director from company B, we realized that he faced another challenge, when the organization didn't have many projects, its team didn't even prioritize the knowledge management, because they had the urgency to sell new projects. For both organizations the knowledge obtained could be, and commonly was reapplied but it kept on the tacit level. To better address the challenges faced among the organizations, Table 5 was generated.

For organization $\mathrm{A}$, the knowledge was more commonly transferred among members of the same project or department, while the transfer of this knowledge to other groups and departments seems to be hampered. Also, it was perceived a hardship of communication, due to the technologies and mechanisms developed, because of this the knowledge keeps in the individual level. This gap in communication is aggravated due to the turnover, causing the knowledge necessary for the execution of the projects to be lost. In addition to all these challenges the organization also has a goal alignment deviation. While the strategic leaders developed the process of knowledge management and its tools, the managerial level keeps prioritizing the project implementation, generating the non-dissemination of new practices and processes.

For organization B the challenges vary. The first perceived challenge is due to the documentation fulfillment timing, the lessons learned are fulfilled in the end of the project. This causes a loss of knowledge during the 
Table 5. Challenges faced by the organizations A and B.

\begin{tabular}{|c|c|c|}
\hline & Organization A & Organization B \\
\hline \multirow{6}{*}{$\begin{array}{l}\text { Challenges faced while managing } \\
\text { knowledge among projects }\end{array}$} & - managerial, operational, and strategic & · Lessons learned fulfillment time; \\
\hline & - Time pressure; & $\begin{array}{l}\text { Paper print: probability of document loss and } \\
\text { difficulty finding the desired event; }\end{array}$ \\
\hline & $\begin{array}{l}\text { - Knowledge management among groups and } \\
\text { departments; }\end{array}$ & · Prioritization of knowledge management; \\
\hline & $\begin{array}{l}\text { - Lack of communication technologies and } \\
\text { mechanisms; }\end{array}$ & - Capability development \\
\hline & · Turn over and lack of capabilities; & \\
\hline & $\begin{array}{l}\text { Sharing of vision and goals between the } \\
\text { organization's strategic and management levels. }\end{array}$ & \\
\hline
\end{tabular}

process. The kind of documentation is also a challenge because it's paper print. In this type of documentation, material losses are as common as the difficulty of accessing an old document. The prioritizing of knowledge management also appears as a challenge once the organization needs to focus on knowledge management and release employees from the project execution and commercialization activities. The last challenge perceived is the development of capabilities of identifying and clearly document the past event.

In agreement with Ghosh et al. (2012) interviewees from both companies addressed the need to a different governance among projects, it would be expected that the employees would rather have a more open governance, as a network for example, but they addressed the need to a more empowered governance, with a well-defined responsibility (Reich et al., 2012).

The structures of the organizations were as different as their cultures, but we perceived that none of them were fully successful while implementing knowledge management. But the leadership (management level) of organization B, which was more knowledge-based, and from a young organization, appeared to understand the concepts and benefits of knowledge management more, but the knowledge management and transfer are hardened due to the culture of the organization, the organization didn't delegate activities if not needed, and doing so the employees didn't seek for different knowledge. On the other hand, organization A is older, and its decisions were politic-based, as pointed by one of the engineers, doing so the board of the organization sees the need of knowledge management but the leadership was not aware of the benefits and real need for doing so, and they posed a barrier for knowledge dissemination. We realized that the organization structure and culture have a direct impact on knowledge management, and different kinds of structures represent different kinds of challenges for knowledge management. In both cases there was a need to train the employees to understand and perform the knowledge management practices, in addition to organization A the projects which occurred during the political crises went through hardships due to the bankruptcy of some suppliers.

In despite of the kind of learning prioritized we perceived that for organization A, the focus was strategic, but several operational and technical challenges were common to be found, but managerial ones were also frequent. So, for this organization, the prioritization didn't appear to be efficient once the operational challenges were recidivists, as pointed by the field engineer. In organization B we found that there was no agreement among the employees about the focus of the knowledge management, but the major challenges happened in managerial situations. The employees were aware of the procedures, documentations and knowledge involved in the project, but there was a corporate culture of not turning to these files when a new project began, they all seemed too worried about their own scope of work and couldn't see the big picture of the projects and knowledge management, thus not giving the due importance to them.

\section{Conclusion, limitation and future implications}

In this paper we proposed to study the factors that affect the knowledge management among project management, we did this through a multiple case study applied to companies presented in different environments.

All the research questions proposed were answer. The first research question: How do the project-based organizations acquire, manage and transfer knowledge? Was answered through complete the results collected and was summarized on Table 4. Codification, sharing, mechanisms of knowledge storage and meetings, are the most common processes for knowledge acquisition, management, and transfer.

The second research question: What are the main challenges the project-based organization faces while managing knowledge? Different types of challenges were perceived, such as organizational alignment, type of documentation, employee skills. The main challenges identified in the data collection were summarized in Table 5 to better understand the results. 
During our interviews we realized that the employees assert great responsibility to the governance structure and empowerment of the organization, employees from both companies addressed a need to an empowered responsible for the learning among projects. There's also a need for personal development, and culture modification among the employees. The lack of proper communication jeopardizes learning in general.

The first organization, an older and with more hierarchical structure, sees the challenges of its implementation on the managerial level, on the other hand the second organization which has a younger layout, and is more focused on self-development, understands the implications of knowledge management better even though they still can't measure it, for this organization the challenge is how to perform knowledge management practices on daily activities.

For each company the kinds of challenges addressed are different, both focus more on managerial and strategic aspects, but for the first organization several challenges and negative results are due to operational issues, showing that they are not addressing the whole need. Each employee sees their own department need for improvement and growth but no one seems to agree on a general need for the company. For the second organization, the operational challenges don't seem to be critical, this may happen due to the high level of tacit knowledge among the employees.

The results also point to barriers occurrence due to the presence of many projects and emergent activities, but there are also barriers to the implementation of knowledge management when the projects portfolio is not fulfilled. Which raises a question about the influence of the business environment in the knowledge management.

The results also point that the players among the organization don't understand the sustainability aspects and team's impact as motivation for managing the knowledge. This result may lighten another aspect of the organizations, which is the lack of consideration with the triple bottom line aspects.

This paper contributes to the literature by pointing the mechanisms each organization use to storage, manage, and transfer the knowledge, and the challenges to perform these activities efficiently. The paper also brings data to analyze the effect that organizational culture, structure, governance, and economic situation on knowledge management practices.

Despite all our contributions, our paper has its own limitations, to start with we applied it to two kinds of organizations, and it shouldn't be generalized to other kinds of companies. Besides that, the literature lacks a quantitative study to address the impact of the factors mentioned above on the knowledge management.

\section{Acknowledgements}

The authors gratefully acknowledge the financial support of the Brazilian research funding agencies CNPq (National Council for Scientific and Technological Development), and CAPES (Federal Agency for the Support and Improvement of Higher Education).

\section{References}

Aerts, G., Dooms, M., \& Haezendonck, E. (2017). Knowledge transfers and project-based learning in large scale infrastructure development projects: an exploratory and com- parative ex-post analysis. International Journal of Project Management, 35(3), 224-240. http:// dx.doi.org/10.1016/j.jproman.2016.10.010.

Alkhuraiji, A., Liu, S., Oderanti, F. O., \& Megicks, P. (2016). New structured knowledge network for strategic decision-making in IT innovative and implementable projects. Journal of Business Research, 69(5), 1534-1538. http://dx.doi.org/10.1016/j.jbusres.2015.10.012.

Andersen, S. S., \& Vidar Hanstad, D. (2013). Knowledge development and transfer in a mindful project-organization. International Journal of Managing Projects in Business, 6(2), 236-250. http://dx.doi.org/10.1108/17538371311319007.

Antoni, M., Nilsson-Witell, L., \& Dahlgaard, J. J. (2005). Inter-project improvement in product development. International Journal of Quality \& Reliability Management, 22(9), 876-893. http://dx.doi.org/10.1108/02656710510625194.

Association for Project Management. (2012). APM body of knowledge (6th ed.). Princes Risborough: Association for Project Management.

Ayas, K. (1996). Professional project management: a shift towards learning and a knowledge creating structure. International Journal of Project Management, 14(3), 131-136. http://dx.doi.org/10.1016/0263-7863(95)00080-1.

Bartsch, V., Ebers, M., \& Maurer, l. (2013). Learning in project-based organizations: the role of project teams' social capital for overcoming barriers to learning. International Journal of Project Management, 31(2), 239-251. http://dx.doi.org/10.1016/j.jproman.2012.06.009.

Baskerville, R., \& Pries-Heje, J. (1999). Knowledge capability and maturity in software management. The Data Base for Advances in Information Systems, 30(2), 26-43. http://dx.doi.org/10.1145/383371.383374.

Bell, L., van Waveren, C. C., \& Steyn, H. (2016). Knowledge-sharing within the project-based organizsation: a knowledge-pull framework. South African Journal of Industrial Engineering, 27(4), 18-33. http://dx.doi.org/10.7166/27-4-1580.

Bernroider, E. W. N., Wong, C. W. Y., \& Lai, K. (2014). From dynamic capabilities to ERP enabled business improvements: the mediating effect of the implementation project. International Journal of Project Management, 32(2), 350-362. http://dx.doi.org/10.1016/j. ijproman.2013.05.006. 
Bingham, C. B., Heimeriks, K. H., Schijven, M., \& Gates, S. (2015). Concurrent learning : how firms develop multiple dynamic capabilities in parallel. Strategic Management Journal, 36(12), 1802-1825. https://doi.org/10.1002/smj.2347.

Carvalho, M. M., \& Rabechini Junior, R. (2015). Impact of risk management on project performance: the importance of soft skills. International Journal of Production Research, 53(2), 321-340. http://dx.doi.org/10.1080/00207543.2014.919423.

Choi, B., \& Lee, H. (2003). An empirical investigation of KM styles and their effect on corporate performance. Information \& Management, 4O(5), 403-417. http://dx.doi.org/10.1016/S0378-7206(02)00060-5.

Chuanmin, S., Bing, G., \& Lu, Z. (2012). Anti-poverty project sustainability in rural China: an empirical analysis. Outlook on Agriculture, 41(3), 153-161. http://dx.doi.org/10.5367/oa.2012.0096.

Daghfous, A. (2004). Organizational learning, knowledge and technology transfer: a case study. The Learning Organization, 11(1), 6783. http://dx.doi.org/10.1108/09696470410515733.

Davies, A., \& Brady, T. (2000). Organisational capabilities and learning in complex product systems: towards repeatable solutions. Research Policy, 29(7-8), 931-953. http://dx.doi.org/10.1016/S0048-7333(00)00113-X.

Dubinskas, F. A. (1993). Modeling cultures of project management. Journal of Engineering and Technology Management, 10(1-2), 129-160. https://doi.org/10.1016/0923-4748(93)90061-M.

Duffield, S. M., \& Whitty, S. J. (2016a). Application of the systemic lessons learned knowledge model for organisational learning through projects. International Journal of Project Management, 34(7), 1280-1293. http://dx.doi.org/10.1016/j.jproman.2016.07.001.

Duffield, S., \& Whitty, S. J. (2016b). How to apply the Systemic Lessons Learned Knowledge model to wire an organisation for the capability of storytelling. International Journal of Project Management, 34(3), 429-443. http://dx.doi.org/10.1016/j.jproman.2015.11.004.

Eisenhardt, K. M. (1989). Building theories from case research. Academy of Management Review, 14(4), 532-550. http://dx.doi. org/10.5465/amr.1989.4308385.

Eisenhardt, K. M., \& Graebner, M. E. (2007). Theory building from cases : opportunities and challenges diverse. Academy of Management Journal, 50(1), 25-32. http://dx.doi.org/10.5465/amj.2007.24160888.

Ferreras-Méndez, J. L., Fernández-Mesa, A., \& Alegre, J. (2016). The relationship between knowledge search strategies and absorptive capacity: a deeper look. Technovation, 54, 48-61. http://dx.doi.org/10.1016/j.technovation.2016.03.001.

Garcias, F., Dalmasso, C., \& Sardas, J. C. (2015). Paradoxical tensions in learning processes: Exploration, exploitation and exploitative learning. Management (France), 18(2), 156-178.

Ghosh, S., Amaya, L., \& Skibniewski, M. J. (2012). ldentifying areas of knowledge governance for successful projects. Journal of Civil Engineering and Management, 18(4), 495-504. http://dx.doi.org/10.3846/13923730.2012.700642.

Grabher, G., \& Thiel, J. (2015). Projects, people, professions: trajectories of learning through a mega-event (the London 2012 case). Geoforum, 65, 328-337. http://dx.doi.org/10.1016/j.geoforum.2015.02.006.

Grigoriou, K., \& Rothaermel, F. T. (2017). Organizing for knowledge generation: internal knowledge networks and the contingent effect of external knowledge sourcing. Strategic Management Journal, 38(2), 395-414. https://doi.org/10.1002/smj.2489.

Hartmann, A., \& Dorée, A. (2015). Learning between projects: more than sending messages in bottles. JPMA, 33(2), 341-351. http:// dx.doi.org/10.1016/j.jproman.2014.07.006.

Khedhaouria, A., Montani, F., \& Thurik, R. (2017). Time pressure and team member creativity within R \& D projects : The role of learning orientation and knowledge sourcing. International Journal of Project Management, 35(6), 942-954. http://dx.doi.org/10.1016/j. ijproman.2017.04.002.

Leseure, M. J., \& Brookes, N. J. (2004). Knowledge management benchmarks for project management. Journal of Knowledge Management, 8(1), 103-116. http://dx.doi.org/10.1108/13673270410523943.

Loufrani-Fedida, S., \& Saglietto, L. (2016). Mechanisms for managing competencies in project-based organizations: an integrative multilevel analysis. Long Range Planning, 49(1), 72-89. http://dx.doi.org/10.1016/j.lrp.2014.09.001.

Love, P. E. D., Teo, P., Davidson, M., Cumming, S., \& Morrison, J. (2016). Building absorptive capacity in an alliance: Process improvement through lessons learned. International Journal of Project Management, 34(7), 1123-1137. http://dx.doi.org/10.1016/j. ijproman.2016.05.010.

Mahanty, S., Stacey, N., Holland, P., Wright, A., \& Menzies, S. (2007). Learning to learn: designing monitoring plans in the Pacific lslands International Waters Project. Ocean and Coastal Management, 50(5-6), 392-410. http://dx.doi.org/10.1016/j.ocecoaman.2006.09.004.

McClory, S., Read, M., \& Labib, A. (2017). Conceptualising the lessons-learned process in project management: Towards a triple-loop learning framework. International Journal of Project Management, 35(7), 1322-1335. http://dx.doi.org/10.1016/j.jproman.2017.05.006.

Medina, R., \& Medina, A. (2017). Managing competence and learning in knowledge-intensive, project-intensive organizations. International Journal of Managing Projects in Business, 10(3), 505-526. http://dx.doi.org/10.1108/lJMPB-04-2016-0032.

Morioka, S. N., Bolis, 1., Evans, S., \& Carvalho, M. M. (2018). Transforming sustainability challenges into competitive advantage: Multiple case studies kaleidoscope converging into sustainable business models. Journal of Cleaner Production, 167, 723-738. http://dx.doi. org/10.1016/j.jclepro.2017.08.118.

Nadae, J. D., \& Monteiro de Carvalho, M. (2017). A knowledge management perspective of the project management office. Brazilian Journal of Operations \& Production Management, 14(3), 350. http://dx.doi.org/10.14488/BJOPM.2017.v14.n3.a8.

Nonaka, l., \& Takeuchi, H. (1997). Criação de conhecimento na empresa: como as empresas japonesas geram a dinâmica da inovação. Rio de Janeiro: Campus

Ravichandran, T., \& Rai, A. (2003). Structural analysis of the impact of knowledge creation and knowledge embedding on software process capability. IEEE Transactions on Engineering Management, 50(3), 270-284.

Reich, B. H., Gemino, A., \& Sauer, C. (2012). Knowledge management and project-based knowledge in it projects: a model and preliminary empirical results. International Journal of Project Management, 30(6), 663-674. http://dx.doi.org/10.1016/j.jproman.2011.12.003.

Sastre-Merino, S., Negrillo, X., \& Hernández-Castellano, D. (2013). Sustainability of rural development projects within the working with people model: application to Aymara Women Communities in the Puno Region, Peru. Cuadernos de Desarrollo Rural, 10(70), 219-244. 
Stephens, J. P., \& Carmeli, A. (2016). The positive effect of expressing negative emotions on knowledge creation capability and performance of project teams. International Journal of Project Management, 34(5), 862-873. http://dx.doi.org/10.1016/j.ijproman.2016.03.003.

Swan, J., Scarbrough, H., \& Newell, S. (2010). Why don't (or do) organizations learn from projects? Management Learning, 41(3), 325344. http://dx.doi.org/10.1177/1350507609357003.

von Zedtwitz, M. (2002). Organizational learning through post-project reviews in R\&amp;D. $R$ \& D Management, 32(3), $255-268$. http://dx.doi.org/10.1111/1467-9310.00258.

Williams, T. (2008). How do organizations learn lessons from projects - and do they? IEEE Transactions on Engineering Management, 55(2), 248-266. http://dx.doi.org/10.1109/TEM.2007.912920.

Yan-Feng, C., \& Xiao-Qiong, H. (2013). Empirical research on the affecting factors of knowledge transfer efficiency in CoPS R\&D project. Mediterranean Journal of Social Sciences, 4(9), 696-700. http://dx.doi.org/10.5901/mjss.2013.v4n9p696.

Yap, J. B. H., Abdul-Rahman, H., \& Chen, W. (2017). Collaborative model: managing design changes with reusable project experiences through project learning and effective communication. International Journal of Project Management, 35(7), 1253-1271. http:// dx.doi.org/10.1016/j.jproman.2017.04.010.

Yin, R. K. (2010). Estudo de caso: planejamento e métodos. 4. ed. Porto Alegre: Bookman.

Zhang, L., \& Li, X. (2016). How to reduce the negative impacts of knowledge heterogeneity in engineering design team: exploring the role of knowledge reuse. International Journal of Project Management, 34(7), 1138-1149. http://dx.doi.org/10.1016/j.jproman.2016.05.009. 


\section{Appendix A}

Check all that apply

a) Knowledge (know-how, technical skill, or problem-solving methods) is well encoded in my company

b) Knowledge can be easily acquired through formal documents and manuals in my company

c) The results of the projects and meetings should be documented in my company

d) Knowledge is shared through coded forms such as manuals or documents in my company

e) My knowledge can be easily acquired by specialists and co-workers of my company

f) It is easy to get face to face advice from my company's specialists

g) Dialogues and informal meetings are used to share knowledge in my company

h) Knowledge is gained through one-on-one mentoring in my company

i) Often, we scan the environment for new technologies.

j) We fully observe technological trends.

k) We observe in detail external sources of new technologies.

1) We organize special meetings with external partners to acquire new technologies.

m) Officials regularly approach external institutions to acquire technological knowledge.

n) We often transfer technological knowledge to our company in response to technology acquisition opportunities.

o) We maintain relevant knowledge over time

p) Employees store technological knowledge for future reference

q) We communicate relevant knowledge in the units of our company.

r) By recognizing a business opportunity, we can quickly rely on our existing technological knowledge.

s) We quickly analyze and interpret changes in market demands for our technologies.

t) New opportunities to serve our customers with existing technologies are quickly understood.

u) We are proficient in transforming technological knowledge into new products.

v) We regularly combine new technologies with ideas for new products.

w) We quickly recognize the usefulness of new technological knowledge for existing knowledge.

x) We regularly apply technologies to new products.

y) We constantly see how to better exploit the technologies.

z) lt is well known who can better exploit new technologies within our company.

01. How many projects did you work in your company?

02. How many of them did you do any kind of post project review?

03. Would you encourage your organization to?

a) conduct more post-project-reviews?

b) conduct less post-project-reviews?

c) conduct the current amount of post-project-reviews?

04. In Your department how often do you conduct post-project reviews?

a) Never;

b) Ad-hoc after some projects;

c) Only after unsuccessful projects;

d) Only after successful projects;

e) After large projects or programs mostly;

f) After most projects;

g) After every project;

05. How are the post- project reviews managed in your department?

a) There are no established post project reviews;

b) Post-project reviews are conducted by external facilitators;

c) A department or unit has been assigned with post project reviews responsibility; 

d) Post project reviews guidelines are 'available upon request';
e) Sound review practices have been defined - everyone knows them;
f) Post project reviews are conducted based on similar earlier reviews;

06. How is the know-how from one project disseminated to other projects?
a) Post project reviews results are poorly implemented in subsequent projects;
b) Know-how is passed on mainly through individuals moving to new projects;
c) Project know how is put down in writing which is accessible for future projects;
d) As part of most post project reviews, the recipients of the review results are identified and notified;
e) Post project review results are effectively used to improve project management;
f) Post project reviews are a consistent and integral part of inter project learning

07. What is the focus and quality of content of your post project reviews?

a) Post project reviews focus mostly on technical issues;

b) Post project reviews focus mostly on managerial issues;

c) Post project reviews focus mostly on strategic issues;

d) The benefits of a post project review depend mainly on the capabilities of all team members;

e) A large amount of review time is devoted to analyzing project management;

f) Sound and consistent review criteria are applied to every post project review;

g) Post project review goals have been quantified and are measurable;

h) The quality of the review results is independent from the projects reviewed and the individuals involved;

08. In your opinion how successful was this project
a) It wasn't a success;
b) Not as good as could be;
c) Satisfactory;
d) We hoped for better;
e) Excellent

09. In this project we had more benefits than loss.
a) 1 completely agree;
b) 1 Agree;
c) 1 neither agree nor disagree;
d) 1 disagree;
e) 1 completely disagree;

10. 1 learned more with hits than misses.
a) 1 completely agree;
b) 1 Agree;
c) 1 neither agree nor disagree;
d) 1 disagree;
e) 1 completely disagree;

11. What were the challenges faced in the project? Detail your involvement and learning with the project. 